\title{
ANIMAL DE REALIDADES Y ANIMAL LÓGICO. NOTAS SOBRE ZUBIRI Y PEIRCE
}

\author{
MARÍA LIDA MOLLO \\ Università della Calabria
}

\begin{abstract}
RESUMEN: El presente artículo está dividido en dos partes. La primera analiza la recepción española del pragmatismo de acuerdo con la versión de William James en autores como Eugenio d'Ors, Miguel de Unamuno y José Ortega y Gasset. La segunda está dedicada a una confrontación crítica entre las filosofías de Zubiri y de Peirce a partir de su definición de hombre. En semejante contexto, salen a luz algunas significativas analogías: el empleo del concepto de «precisivo", la referencia a la lengua vasca y su relación con una lógica nueva, la actitud anticartesiana, el carácter mediato del «percepto» y el papel que juega lo irreal en su concepto de experiencia y de saber.
\end{abstract}

PALABRAS CLAVE: pragmatismo, pragmaticismo, precisivo, percepto, irreal, experiencia.

\section{Animal of realities and logical animal. Annotations on Zubiri and Peirce}

ABSTRACT: This article is divided into two parts. The first part analyzes Spanish reception of pragmatism according to William James' version in authors such as Eugenio d'Ors, Miguel de Unamuno and José Ortega y Gasset. The second one focuses on a critical comparison between Zubiri's and Peirce's philosophies starting from their definition of man. In that context, some meaningful analogies come up: the use of the concept of "precisive", the reference to Basque language and its relationship with a new Logic, the anti-Cartesian attitude, the mediated character of "percept» and the role which the «Unreal» takes in their concept of experience and knowledge.

KEY WORDS: pragmatism, pragmaticism, precisive, percept, unreal, experience.

\section{Desencuentros, malentendidos y «SECUeStradores» DE Palabras: LA SOMBRA DE W. JAMES}

Un trabajo que intente explorar las afinidades electivas entre el fundador del pragmatismo y el metafísico de la realidad —además de ontólogo de la inteligencia sentiente- debe superar en primera instancia la circunstancia de que el primero, fallecido en el año 1914, no pudo tener noticia del segundo. Y si ello es un dato que nunca ha constituido un obstáculo para ningún ejercicio de hermenéutica filosófica, hay otro que complica los términos de una posible confrontación crítica. A saber, el dato de que Zubiri tiene un conocimiento de Peirce que resulta mediado sensiblemente por la figura de William James, quien ingresó muy tempranamente en el pensamiento español, determinando un rasgo que un historiador de la filosofía del calibre de Julián Marías no podía dejar desatendido. Pues en su afortunado manual - acompañado por un prólogo y un epílogo de excepción - con el que se formaron generaciones de estudiantes, se señalaba el descubrimiento tardío del pensamiento de Peirce, «muy fragmentario y poco sistemático», como una de las causas del «exclusivismo 
de vincular el pragmatismo a James y a sus continuadores inmediatos» ${ }^{1}$. Baste considerar las tempranas referencias de Miguel de Unamuno a The Principles of Psychology, The Will to Believe, The Varieties of Religious Experience y a Pragmatism $^{2}$.

Por cierto no sorprende que el «empirismo radical» de James haya podido empalmar con la instancia antipositivista unamuniana. De ello constituye una prueba fehaciente la actitud que comparten contra la «pulverización de los hechos». En un pasaje de A World of Pure Experience, James rechaza resueltamente la tendencia a eliminar las conexiones entre las cosas y a insistir sobre todo en las disyunciones, una tendencia que caracterizaría tanto a la filosofía de Berkeley como a la de Hume, pero también a la de John Stuart Mill. El blanco polémico hacia el cual lanzar el reto del empirismo radical es entonces «la consideración de John Mill sobre las cosas físicas como compuestos de posibilidades discontinuas, y la general pulverización de toda experiencia mediante asociación, así como la teoría del "Mind-dust" "». Por otra parte, en Del sentimiento trágico de la vida, leemos que «anduvo no ha mucho tiempo por el mundo una cierta doctrina que llamábamos positivismo, que hizo mucho bien y mucho mal. Y entre otros males que hizo, fue el de traernos un género tal de análisis, que los hechos se pulverizaban con él, reduciéndose a polvo de hechos» ${ }^{4}$. En semejante consonancia, en esta común elección, no de negar el positum, sino de partir de él preservándolo de las fragmentaciones, que impulsa a James a decir que "para ser radical, un empirismo no puede admitir en sus construcciones ningún elemento que no sea directamente experimentado», es posible captar uno de los puntos de incompatibilidad entre James y la actitud analítica de Peirce. A saber, una actitud, un método y un estilo inspirados, según lo que él mismo declara ${ }^{5}$, por un lado, en las investigaciones de laboratorio y, por otro, en la filosofía de Kant. Claro que la teoría de la percepción que expone Peirce y, en particular, el gesto teórico con el que alcanza un elemento originario que no se deja pensar, es decir, el feeling o cualidad de sensación, más

1 Marías, J. (1941), Historia de la filosofía, con prólogo de ZuBIRI, X. y epílogo de OrTEga y GASSET, J. Madrid: Revista de Occidente, pp. 383 y 384. (Cito por la vigésimo quinta edición de 1973).

2 Para un examen pormenorizado de la lectura unamuniana de estas cuatro obras de James, remito a la exhaustiva tesis doctoral de Martínez Martín, I. (2006), William James y Miguel de Unamuno: una nueva evaluación de la recepción del pensamiento pragmatista en España. Pamplona: Universidad de Navarra.

3 JAMES, W. (1904), «A World of Pure Experience», Journal of Philosophy, Psychologie and Scientific Methods, vol. 1, 20 y 21, pp. 533-543 y 561-570; trad. es. de Robador, O. http:// www. unav.es/gep/PuraExperiencia.html.

4 Unamuno, M. DE $(1913,2002)$, Del sentimiento trágico de la vida. Barcelona: Ediciones Folio, p. 9.

5 Cfr. el texto publicado en el Monist en el año 1905 «Issues of Pragmaticism», en PeIRCE, Сн. S. (1931-58), Collected Papers of Charles Sanders Peirce, 8 vols. Cambridge: Harvard University Press, vol. 5, parágrafos 438-463. De ahora en adelante, de acuerdo con la forma tradicional de citarlos, se utilizará la sigla $\mathrm{CP}$ seguida por el número del volumen y del parágrafo. 
originario que la sensation, o sensación en sentido estricto (que es justamente una hipótesis y como tal tiene un carácter mediato) nada tiene que ver con la simple sucesión de hechos atómicos de Mill. Podríamos decir, anticipando un aspecto que intentaremos desarrollar más adelante, que el estilo analítico, por no decir la "triadomanía» ${ }^{6}$ — tal y como la llamó Peirce en respuesta a la sospecha anticipada de que «se otorga una importancia supersticiosa o fantástica al número tres y fuerza a divisiones para un lecho de Procusto de la tricotomía»- sin embargo, debe leerse de acuerdo con la íntima relación que guarda con la «continuidad», que es el tema en el que se concentrará la perseverancia y la persistencia de Peirce (Peirce-everance y Peirce-istence, según sus frecuentes juegos de palabras $)^{7}$ y, por el lado de Zubiri, con el vínculo que liga la actualización de la «aprehensión primordial de realidad» a las reactualizaciones del «logos» y de la «razón».

Retomando la cuestión de la recepción española del pragmatismo, no se puede sino mencionar a Eugenio d'Ors, que en París asiste a las clases de Bergson y de Boutroux y en el año 1907 escribe la glosa «Pragmatisme», en la que se define como un pragmatista, pero no sin exhibir los rasgos de lo que podríamos llamar un ultra-pragmatismo, una superación del mismo en clave estética o, mejor dicho, ese «intelectualismo post-pragmático» que habría dado forma a su primer libro de filosofía, publicado en el año 1914, La filosofía del hombre que trabaja y que juega ${ }^{8}$. Según ya ha sido puesto de manifiesto ${ }^{9}$, las fuentes en la redacción de la glosa «Pragmatisme» son el Dictionary of Philosophy and Psychology editado por James A. Baldwin y el pragmatismo en una versión que resulta claramente de cuño jamesiano, sobre todo si se considera la asimilación del pragmatismo al utilitarismo. Pero que d'Ors esté pensando en James y no en Peirce lo demuestra aún más claramente el hecho de que pretende superar a aquellos que «rehúsan la Lógica sistemática, la Construcción, reduciéndose a una metafísica improvisadora», y semejante superación debe ejercerse —a su juicio_ - acudiendo a la armonía y a la belleza de las construcciones, ahí donde

6 CP 1.568-572.

7 «Todo lo que logré hacer está debido a dos cosas, la primera, una perseverancia como la de una avispa en una botella, y, la segunda, el feliz accidente de haber topado muy tempranamente con un método de pensamiento que toda persona inteligente puede gobernar» [MS L 387. Carta remitida al juez F. C. Russell del 15 de noviembre de 1904, cit. en BRENT, J. (19982), Charles Sanders Peirce: A Life. Bloomington-Indianapolis: Indiana University Press, p. 322 y ss.].

8 D'Ors, E. (1995), La filosofía del hombre que trabaja y que juega. Madrid: Libertarias/ Prodhufi, pp. 62-63. A. González y J. Nubiola muestran la persistencia, en todo el itinerario intelectual de d'Ors, de la confrontación crítica con James, quien, colocado en el periodo de "fin-de-siglo», en el eón de lo barroco, constituye un referente polémico constante, GonZÁLEz, A., Nubiola, J. (2007), «William James en Eugenio d’Ors», Anuario Filosófico, xL/2, pp. 413-433.

9 Torregosa, M. (2003), Filosofía y vida de Eugenio d'Ors: etapa catalana, 1881-1921. Pamplona: Ediciones Universidad de Navarra, pp. 71-74. 
se halla, «más que en su utilidad, la fuente profunda de su verdad» ${ }^{10}$. Es evidente que entre «aquellos» no puede insertarse de ninguna manera a Peirce, quien en la primera de las siete conferencias dictadas en Harvard desde marzo hasta mayo de 1903, a la hora de abordar las relaciones de las ciencias normativas, definía a la estética como «la ciencia normativa básica sobre la que, como un fundamento, debe erigirse la doctrina de la ética para ser coronada a su vez por la doctrina de la lógica» ${ }^{11}$.

Además de esto, cabe recordar que d'Ors participó en el III Congreso Internacional de Filosofía celebrado en Heidelberg en el año 1908 con dos comunicaciones, «El residuo en la medida de la ciencia por la acción» $\mathrm{y}$ «Religio est libertas», en las que resulta evidente una recepción que es al mismo tiempo superación. Y también aquí, en particular en la segunda comunicación, la referencia, aunque no aparece citado directamente, apunta a James y a su reducción de la religión a fenómenos psicológicos. En neto contraste con un estudio científico de la religión, d'Ors reivindica que la religión es el ámbito de la libertad y «la libertad no constituye materia de ciencia, sino un imperativo de creencia» ${ }^{12}$.

Como resulta claro, la confrontación de d'Ors con el pragmatismo no solo reconfirma ese rasgo de la recepción que hemos visto caracterizar como «exclusivismo» de James, sino que en la misma superación del pragmatismo ${ }^{13}$, en su afán de conciliar el interés por los fenómenos vitales ${ }^{14}$ con una idea de razón

10 D’Ors, E. (1996), «Pragmatisme», en Glosari 1907-1907. Barcelona: Quaderns Crema, pp. $729-730$.

11 CP 5.36. Cfr. también CP 5.132, que arroja luz sobre el motivo por el que la lógica depende de la ética y esta de la estética. En pocas palabras, si lo verdadero es una parte de lo justo, y lo justo es una parte de lo admirable, esto ultimo posee una multiplicidad de partes tan relacionadas unas con otras que imparten una simple cualidad positiva a su totalidad. «An object, to be esthetically good, must have a multitude of parts so related to one another as to impart a simple positive quality to their totality».

12 Elsenhans, T. (ed.) (1909), Bericht über den III. Internationalen Kongress für Philosophie zu Heidelberg 1. bis 5. September 1908. Heidelberg: Carl Winter's Universitätsbuchhandlung.

13 Cabe recordar que en la traducción al castellano de la glosa «Pragmatisme» que aparece en la edición Glosas. Páginas del Glosari de Xenius de 1920, d’Ors suprimió la frase en la que aparecía su afiliación al pragmatismo. Cfr. Torregrosa, M. (2007), «El pragmatismo en el pensamiento de Eugenio d'Ors», Anuario Filosófico, xL/2, pp. 373-387, en especial p. 386.

14 Al respecto no es baladí recordar un pasaje de las Harvard Lectures on Pragmatism, en el que Peirce narra del distinto modo como él y Chauncey Wright acogieron El origen de las especies de Darwin. Pues mientras que para Wright — que había sido hamiltoniano, luego defensor del «nominalismo de John Stuart Mill» y que adoptaba una perspectiva mecanicista- «las doctrinas de Darwin le parecían como una suerte de suplemento a las de Mill», para Peirce, en cambio, eran como «una enredadera pegada al árbol del asociacionismo»y «al cabo de algún tiempo, esa enredadera mataría inevitablemente al árbol». Lo que más nos interesa es la siguiente autodefinición: «Cuál sea la verdadera definición del pragmatismo es algo que me resulta muy difícil de decir; pero, en mi naturaleza, es una especie de atracción instintiva por los hechos vitales» (CP 5.64). 
flexible, ampliada y abierta a los elementos de experiencia, gusto e intuición ${ }^{15}$ es posible detectar, tal como se ha hecho ${ }^{16}$, no pocos elementos de afinidad con el «pragmaticismo», a saber, con la posición de quien se vio obligado a cambiarle

15 Véase el concepto de seny que aparece en el ya citado texto La filosofía del hombre que trabaja y que juega y el «pensamiento figurativo» de la obra de 1947, El secreto de la filosofía. Barcelona: Iberia. Sobre el seny como rasgo distintivo de la así llamada «Escuela de Barcelona» o, según la expresión que prefiere Nicol, koinonía catalana, véase E. Nicol (1998²), El problema de la filosofía hispánica. México: FCE, pp. 169-207, en especial p. 198: «El seny (...), del cual se ha dicho que es un rasgo notorio del ethos catalán, es una forma medieval y autóctona de la sagesse o sapiencia, entendida como capacidad del hombre mesurado y de buen consejo que rechaza todo lo extravagante y lo desorbitado; y esta forma, con variaciones e influencias diversas, podría reseguirse desde el Libre de Saviesa del siglo XIII hasta la bondad sin aparato de Serra Hunter, pasando por el Libre de Blanquerna de Raimundo Lull y las poesías de Auziàs March».

16 Cfr. Nubiola, J. (1995), «Eugenio d'Ors: una concepción pragmatista del lenguaje», Revista de Filosofía, 3a época, vIII/13, pp. 49-56, en especial pp. 53-55, donde Nubiola señala los siguientes rasgos comunes entre d’Ors y Peirce: el carácter triádico de la relación de significación, las clasificaciones taxonómicas ternarias, el anticartesianismo y el antisolipsismo, la concepción social del conocimiento, el falibilismo de la ciencia, la provisionalidad del saber, y la presencia en d'Ors de la abducción, entendida como «la intuición que brota en el choque del diálogo, pero que requiere el calor del estudio». Nubiola llega a detectar en El secreto de la filosofía la «anticipación de la semiosis ilimitada de Umberto Eco y el reemplazo de la noción estructuralista de "código" por la mucho más rica de "enciclopedia"» (p. 54). Cfr. también Torregrosa, M. (2007), «El pragmatismo en el pensamiento de Eugenio d'Ors», pp. 385-386, que además de compartir las afinidades señaladas por Nubiola, destaca, en lo que concierne al origen de la creatividad científica, las similitudes que guarda el instinto del juego lógico llamado «curiosidad» con la abducción (p. 386). A este respecto, cabe mencionar la relación que Peirce establece entre guessing, la expresión galileiana lume naturale y abducción. Pues es justamente la capacidad de adivinar (guessing right) la que ha determinado «la cantidad de conocimiento que hoy está a disposición del peor imbécil» (CP 2.753). Y si a Galileo le sirvieron unos pocos experimentos para establecer las bases de la mecánica, ello es porque «su principal punto de apoyo era el sentido común e il lume naturale» (CP 6.10). El guessing es entonces un instinto: «Nuestra capacidad de adivinar se corresponde con los poderes canoros y aeronáuticos de un pájaro; a saber, ella es para nosotros, al igual que aquellos para ellos, el más elevado de los poderes meramente instintivos» (CP 7.48). Sobre este aspecto cfr. FADDA, E. (2013), Peirce. Roma: Carocci, p. 100: «El guessing no debe ser puesto en relación con la abducción como forma de inferencia, sino con la relación entre la abducción y la verdad científica, y es algo que guía ante todo a la abducción sobre las abducciones (la apuesta por la apuesta que hay que adoptar)». Además de identificar el guessing con la meta-abducción de Eco [Eco, U.(1990), I limiti dell'interpretazione. Milán: Bompiani, p. 254], que da al hombre el coraje para desafiar el falibilismo, Fadda plantea, al hilo de Peirce, una pregunta capital que halla una respuesta parcial. La pregunta sobre qué es lo que explica el poder adivinatorio de acertar (guessing right) por parte del hombre y de todo lo orgánico (CP 2.86) halla una respuesta en el hecho de que «la retroducción procede según la esperanza de que hay aquí suficiente afinidad entre la mente del razonador y la naturaleza para hacer la conjetura no enteramente desesperanzada, con tal que cada conjetura sea revisada comparándola con la observación» (CP 1.121). Véase la lectura que realiza Giovanni Maddalena del instinto racional a lo largo de todo el itinerario especulativo peirceano. Maddalena halla en el instinto racional, más que en el pragmatismo, la verdadera riqueza de la lógica que conduce al reconocimiento de una realidad metafísica [Maddalena, G. (2009), Metafisica per assurdo. Peirce e i problemi dell'epistemologia contemporanea. Soveria Mannelli: Rubbettino]. 
el nombre a su propio hijo, a un hijo que se había desdoblado y multiplicado, y que por eso mismo tenía más de un destino (el empirismo radical de James y el «antropomorfismo» de F. C. S. Schiller) y de un nombre. Nos referimos al célebre pasaje del artículo de Peirce publicado en el Monist en el año 1905 que lleva justo el título «What pragmatism is?»

«El escritor, al encontrar su dichoso "pragmatismo" promovido de esta forma, siente que ya es tiempo de dar a su criatura un beso de despedida y permitirle ascender hacia su más elevado destino; mientras que para servir al preciso propósito de expresar la definición original, tiene el gusto de anunciar el nacimiento de la palabra "pragmaticismo", que es lo suficientemente fea para estar a salvo de secuestradores ${ }^{17}$.

Además de la ironía con la que libera al hijo entregándolo al higher destiny de la psicología, Peirce escoge la forma de la tercera persona para cumplir una tarea que es su propia ética terminológica la que la exige, y a la que responde estipulando el término «pragmaticismo» para distinguirlo del pragmatismo practicalista de James. Por otra parte, la elección de la tercera persona ${ }^{18}$ está íntimamente relacionada con una estrategia en la que es fácil reconocer el papel central que juega el testimonio de los otros en todo su itinerario especulativo. Piénsese, por ejemplo, en el texto que Peirce afirmaba ser su «única contribución a la filosofía» ${ }^{19}$ : «On a New List of Categories» del año 1867. Pues bien, en esta reescritura de las categorías, en la que se arranca de la idea contenida en la Analítica trascendental de la Crítica de la razón pura, según la cual la función de los conceptos es reducir a unidad la multiplicidad de las impresiones sensibles, se propone una gradación entre conceptos universales, en la que se destacan dos polaridades, la categoría de Ser y la categoría de Sustancia, y en el medio se hallan tres categorías, «a las que se le pueden dar el nombre de accidentes»: cualidad (referencia a un fundamento), relación (referencia a un correlato) y

17 CP 5.414. Este artículo es el primero de una serie de tres sobre el pragmaticismo, de la cual el segundo es «Issues of Pragmaticism» (1905) y el tercero es «Prolegomena for an Apology to Pragmaticism» (1906).

18 Sobre la relación que guardan la elección de la tercera persona, la autobiografía y la dimensión intersubjetiva de la vida y de la narración, cabe recordar la Vita scritta da se medesimo de Giambattista Vico (1723-28). Cfr. Vico, G. (1998), Autobiografía de Giambattista Vico, ed. de González, M. y Martínez Bisbal, J. Madrid: Siglo xxi. Llama la atención sobre la relevancia que posee la elección de semejante estrategia narrativa en Vico y Zambrano, Cacciatore, G. (2007), "La filosofia dello storicismo come narrazione della storia pensata e della storia vissuta», en Cacciatore, G., Giugliano, A. (eds.) (2007), Storicismo e storicismi. Milán: Mondadori, en especial pp. 154-155. Cfr. también Cacciatore, G. (2013), Sulla filosofia spagnola. Saggi e ricerche. Bolonia: il Mulino, p. 110, donde refiriéndose al texto zambraniano Delirio y destino, ahonda en la «continua incesante recíproca transposición entre la primera y la tercera persona» como «un doble movimiento (...) que se instaura en la comunicación entre memoria y conciencia, entre la riqueza de la experiencia vivida (la vivencia) que se deposita magmática y caóticamente en la memoria, que está entretejida de sueños y delirios, y el orden de la conciencia que, a su vez, siempre tiene que volver a la memoria a no ser que quiera quedar osificada e inmóvil en la idolatría del pasado».

19 CP 8.213. 
representación (referencia a un interpretante). De particular interés es la afirmación que se halla unas líneas después de este esquema según la cual «el concepto de yo implica la posibilidad de un otro. El fundamento es el yo abstraído de la concreción que implica la posibilidad del otro ${ }^{20}$. Además, cabe señalar, tal como lo hace Peirce exhibiendo ya desde este artículo un claro tono anticartesiano que desarrollará en escritos inmediatamente sucesivos ${ }^{21}$, que en el paso del ser a la sustancia «no se recurre a la introspección. No se supone nada respecto de los elementos subjetivos de la conciencia que no se pueda inferir de los elementos objetivos ${ }^{22}$. Al respecto, es necesario distinguir entre interpretante e intérprete y, así mismo, tener presente que la semiótica peirceana no se limita a la comunicación entre individuos humanos. Lo cual radica en una idea antipsicológica de mente, según la cual esta última es cualquier posibilidad de interpretar signos ${ }^{23}$.

Una breve incursión en un texto de la «serie anticartesiana» como "Questions Concerning Certain Faculties Claimed for Man», nos permitirá captar el sentido que asume la intersubjetividad en la filosofía de Peirce, que, no obstante su importancia, no adquiere un valor absoluto ${ }^{24}$ : "el testimonio es incluso una marca más fuerte del hecho que los hechos mismos, o mejor que lo que ahora debe pensarse como las propias apariencias. (Dicho sea de paso, observo que es así durante toda la vida; el testimonio le convencerá a un hombre de que está loco). (...) el testimonio proporciona el primer atisbo de la autoconciencia» ${ }^{25}$.

20 CP 1.556.

21 Nos referimos a los ensayos publicados entre el año 1868 y el 1869 en el Journal of Speculative Philosophy: "Questions Concerning Certain Faculties Claimed for Man», "Some Consequences of Four Incapacities» $\mathrm{y}$ «Further Consequences of Four Incapacities: Grounds of Validity of the Laws of Logic».

22 CP 1.550.

23 Sobre este aspecto, cfr. FAdDA, E. (2013), Peirce, pp. 173-175. Fadda, después de haber mencionado la distinción hecha por Karl-Otto Apel que destaca en los Collected Papers peirceanos pasajes en los que prevalece la lectura psicológica y pasajes en los que prevalece la lectura psíquica, declara su preferencia por la visión psíquica, en primer lugar porque no niega, sino que incluye, la visión psicológica y en segundo lugar porque resulta coherente con la dimensión fenomenológica y cosmológica de la filosofía de Peirce. Cfr. Apel, K.-O. (1994), «I: Towards a Trascendental Semiotics», en ID. (1994), Karl-Otto Apel: Selected Essays. Atlantic Highlands: Humanities Press, p. 380. Véase también la posición que expresa Habermas al respecto, que justamente haciendo hincapié en el hecho de que Peirce no hace coincidir el interpretante con el intérprete, habla de una "anonimización del proceso interpretativo» [Habermas, J. (1995), "Peirce and Communication», en Ketner, K. L. (ed.) (1995), Peirce and Contemporary Thought. New York: Fordham University Press, p. 245].

24 Cfr. Calcaterra, R. M. (2003), Pragmatismo: $i$ valori dell'esperienza. Roma: Carocci, p. 28 y s.: La intersubjetividad «remite siempre a la experiencia objetiva como a su ulterior test de verificación y respecto a la cual hay que tener en cuenta el papel "constructivo" que juega cada sujeto. (...). En particular, (...) la intersubjetividad no representa de ninguna manera un criterio decisivo para el acceso epistémico a ese mundo interno, a esos "hechos de la conciencia” que, sin embargo, solamente a través de la confrontación intersubjetiva salen a luz en toda su consistencia. En efecto, aunque es la condición que da origen a la conciencia del propio yo y de su falibilidad, el testimonio tiene una prioridad tan solo de carácter psicológico».

25 CP 5.233. 
Se trata entonces de una prioridad de carácter psicológico y el hecho de que la experiencia objetiva constituya un test de verificación emerge claramente del desarrollo de la «tercera cuestión», aquella que Peirce plantea a través de la pregunta de «si poseemos una capacidad intuitiva de distinguir entre los elementos subjetivos de los diferentes tipos de cogniciones». En pocas palabras, Peirce se pregunta si en dicha diferencia interviene o no una facultad intuitiva. Y la diferencia es la que hay entre ver un color e imaginarlo, entre el sueño más vívido y la realidad. La respuesta la dará asumiendo un criterio objetivista que apunta a excluir la intervención de la facultad intuitiva, gesto, este, que, per incidens, marca la distancia que toma Peirce no solo de su referente polémico explícito, a saber, el espíritu del cartesianismo, sino también - como veremos más adelante y en una confrontación de la que se ha hecho cargo Spiegelberg $^{26}$ - de la fenomenología de Husserl. Por ahora, conviene detenerse en una distinción, que, postergando una vez más la entrada en escena de Zubiri, nos permitirá insertar otra voz española en este breve panorama de la recepción del pragmatismo, nada menos que la de Ortega y Gasset. Pues Peirce pasa a la distinción entre creencia y concepción y afirma:

«Podemos distinguir incuestionablemente una creencia de una concepción, en la mayoría de los casos, por medio de una sensación [feeling] particular de convicción; y es simplemente una cuestión de palabras si definimos la creencia como ese juicio que es acompañado por esta sensación [feeling], o como el juicio en virtud del cual actúa un hombre. Podemos designar al primero como una creencia sensorial y al segundo como una creencia activa (...). Tomando la creencia en el sentido sensorial, la capacidad intuitiva de reorganizarla equivaldrá simplemente a la capacidad para la sensación [sensation] que acompaña al juicio. Esta sensación [sensation], como cualquier otra, es un objeto de conciencia y, en consecuencia, su capacidad no implica un reconocimiento intuitivo de los elementos subjetivos de la conciencia. Si se toma la creencia en el sentido activo, puede ser descubierta por la observación de los hechos externos y por la inferencia a partir de la sensación [sensation] de convicción que suele acompañarla» ${ }^{27}$.

Como ya hemos anticipado, el criterio es objetivo que no subjetivo. Merece ser destacada la asunción de la sensación ${ }^{28}$ como objeto de conciencia, pero de una conciencia, que, a diferencia de la husserliana, no es intencional ni mucho

26 Spiegelberg, H. (1956), «Husserl's and Peirce's Phenomenologies: Coincidence or Interaction», Philosophy and Phenomenological Research, vol. 17/2, pp. 164-185.

27 CP 5.242 .

28 Sobre la diferencia que existe entre dos conceptos cardinales como feeling y sensation, que aquí hemos decidido traducir ambos con sensación, véase el ejemplo del sonido que proporciona Peirce en «Questions Concerning Certain Faculties Claimed for Man»: «El grado de un tono musical depende de la rapidez con la que ciertas impresiones se transmiten sucesivamente a la mente. Estas impresiones deben existir previamente a cualquier tono, de ahí que la sensación (sensation) de grado esté determinada por cogniciones previas. Sin embargo, esto nunca se habría descubierto por medio de la mera contemplación de esa sensación (feeling)» (CP 5.222). 
menos refleja. Y si, tal como asevera Peirce, «no tenemos la facultad intuitiva de distinguir entre diferentes modos subjetivos de conciencia» ${ }^{29}$, entonces parece no haber otra opción que partir del supuesto de que «los objetos inmediatos de dos facultades cualesquiera deben ser diferentes» ${ }^{30}$. Y la claridad y la distintividad, lejos de estar vinculadas con la absoluta dación de las cogitationes, resultan mediadas por la «inferencia a partir de hechos externos» ${ }^{31}$. Cabe aquí recordar que en «How to make our ideas clear» -el texto del año 1878 del que nos ocuparemos más adelante- Peirce se hará cargo de la tarea de esclarecer «nuestras ideas» a partir de la desconstrucción de los conceptos de clearness $\mathrm{y}$ de distinctness, previamente traducidos con «familiaridad» $\mathrm{y}$ «distintividad abstracta $»^{32}$.

Un último caso — según decíamos- merece nuestra atención antes de adentrarnos en la recepción zubiriana del pragmatismo. El caso es el ya anunciado de Ortega y su importancia no reside solo en la circunstancia de haber sido el maestro de Zubiri, sino en el hecho de que sus primeras observaciones acerca del pragmatismo aparecen en una etapa sumamente delicada, un etapa de transición del neokantismo a la fenomenología, una etapa en la que ve la luz su primer libro, Meditaciones del Quijote, y en la que —según declara en la Lección I del curso dictado en el Centro de Estudios Históricos del año 1915 al 1916, que lleva el título «Sistema de la psicología»- le «sobrecoge un temor de nueva especie no experimentado antes ${ }^{33}$ y ello porque ha tomado la decisión de ser un «investigador independiente» encarando "problemas nodales» $\sin$ el amparo de un clásico. Da la pauta de la riqueza de sugestiones, de motivos críticos y del multiverso de ideas y de referencias textuales que constituyen el trasfondo de este periodo sumamente creativo para Ortega, da fe la edición de Paulino Garagorri de Investigaciones psicológicas ${ }^{34}$. Y ello porque, como es sabido, Garagorri decidió acompañar el curso «Sistema de la psicología» con los primeros escritos fenomenológicos: dos textos del año 1913 (la conferencia «Sensación, construcción e intuición» junto con la reseña de la tesis doctoral de Heinrich Hofmann Untersuchungen über den Empfindungsbegriff, que lleva el título "Sobre el concepto de sensación») y los fragmentos "Para un diccionario filosófico». Ahora bien, en semejante constelación de textos, la entusiasta recepción de la fenomenología husserliana se entrelaza con el interés por el concepto de Annahmen de Alexius Meinong, en particular en lo que concierne a esa implicación de negativo y positivo por la cual si, por ejemplo, debo captar el no ser de A, A tiene que darse de alguna manera que no debe coincidir necesariamente con su existencia. Aquí nos interesa sobre todo destacar esos rasgos

29 CP 5.246.

30 CP 5.243.

31 CP 5.249.

32 CP 5.390

33 Ortega y Gasset, J. (2007), Obras completas, vol. vir. Madrid: Taurus, p. 431 (de ahora en adelante $\mathrm{OC}$, VII).

34 Ortega y Gasset, J. (1979), Investigaciones psicológicas. Madrid: Alianza. 
de ambigüedad que caracterizan una recepción que no es mera recepción y que se manifiestan ante todo en la actitud orteguiana hacia el cartesianismo de Husserl. En «Sobre el concepto de sensación», Ortega inserta en la reseña del texto de Hofmann un intermezzo en el que da noticia de la aparición de Ideen I, pero no sin subrayar la novedad del idealismo husserliano respecto al clásico de Platón, Descartes, Leibniz y Kant. La novedad consiste en ser un «idealismo metódico» y, como bien saben los lectores de Ortega, la calificación de «metafísico» que aparece en el año 1929 en el curso «¿Qué es filosofía?» determinará una toma de distancia —más o menos definitiva, según los intérpretes- de la misma fenomenología.

Pero si el cartesianismo husserliano no parece representar un problema, si la epojé es una "puesta entre paréntesis» que (todavía) no implica un acto de aniquilación -como gusta decir Ortega cada vez que se refiere al protagonismo que adquiere la imaginación en la Edad Moderna que reduce las cosas al «darse cuenta»—, la heterodoxia orteguiana se manifiesta en el planteamiento de la relación entre verdad y evidencia. Y también aquí pareciera que la figura de James se interpuso entre quien, como Peirce, había definido la creencia como una regla de acción ${ }^{35}$ y quien, como Ortega, de la relación entre idea y creencia hará el combustible para su reflexión acerca de la historia, para su «Historia como sistema». Pero ahora, en el contexto del curso de 1915-16, en particular en la décima lección, la atención dedicada al escepticismo y la reflexión acerca del plexo conceptual duda-verdad-creencia, cobra un ritmo espasmódico:

«La verdad es el sentimiento de evidencia - la creencia, James, la reacción emocional del hombre entero. - La customary conexion de Hume. Nietzsche: la verdad "es aquella clase de error sin la cual no puede vivir una especie determinada" [...]. La verdad filosófica para Simmel, como el arte, la danza. La verdad es la danza nativa del alma, su módulo y compás» ${ }^{36}$.

Pareciera resonar la respuesta de Peirce a la pregunta que él mismo se plantea: «¿Y qué es, pues, la creencia? Es la semicadencia que cierra una frase musical en la sinfonía de nuestra vida intelectual ${ }^{37}$. Una posible divergencia concierne a la distinta actitud que manifiestan ante el escepticismo. Pues la

35 Véanse los dos primeros de la serie de seis artículos que Peirce publica entre el año 1877 y el 1878 en el Popular Science Monthly: «The Fixation of Belief» y «How to Make our Ideas Clear».

36 OC, VII, pp. 501-502.

37 CP 5.397. Podríamos proseguir con un paralelo entre el carácter líquido que Ortega atribuye a la duda y que conduce al hombre al naufragio y el efecto de irritación que le confiere Peirce. Para ambos, la creencia representa un momento provisorio de salvación (tierra firme en Ortega, regla de acción en Peirce). Sin embargo, cabe señalar una diferencia entre la dialéctica ideas-creencias por la cual para Ortega hay una secuencia del tipo idea-creenciaduda-idea-creencia...(establecido que la primera idea fue la metáfora como instrumento de salvación del naufragio originario y radical que es la vida) y las tres propiedades que Peirce atribuye a la creencia: "primero, es algo de lo que nos percatamos; segundo, apacigua la irritación de la duda, y, tercero, involucra el asentamiento de una regla de acción en nuestra naturaleza, o dicho brevemente, de un hábito» (CP 5.397). 
duda, en el preciso contexto del curso orteguiano que estamos analizando (distinta es la acepción que asume en textos como «Ideas y creencias» e «Historia como sistema»), cobra un valor metodológico que difícilmente habría podido compartir quien, como Peirce, polemizaba con la «duda de papel ${ }^{38}$. Sin salirnos de la lección x leemos lo siguiente: «Como aquella sonata de Beethoven, "a la alegría por el dolor", tenemos que llegar a la verdad por la duda y a la filosofía por el escepticismo» ${ }^{39}$.

La cuestión del escepticismo es una cuestión principal en tanto que íntimamente involucrada en la elección del punto de partida. Baste pensar en Husserl, en el puesto de honor que reserva tanto a Descartes como a Gorgias, «más radical y serio que Protágoras», según asevera en un ciclo de lecciones dictadas en el año 1923 en Friburgo (primera parte de Erste Philosophie), en especial en la novena, que está dedicada precisamente al significado fundamental de la inmortalidad del escepticismo en la historia de la filosofía. Al respecto, merece la pena transcribir el pasaje y la cita de Herbart tal como aparecen en el desorden de la lección x de «Sistema de la psicología»: «El escepticismo no es un episodio de la filosofía, y el escéptico no es un salteador que de súbito saliese al camino real para desvalijar al filósofo transeúnte. (Es todo lo contrario. La filosofía comienza por el escepticismo como la espada por su buida punta. - Herbart-) $)^{40}$.

Otra cita, esta vez de la lección XIII, nos permitirá evidenciar una divergencia sobremanera relevante con Husserl, y con los que serán los «primeros escritos» del joven Zubiri. Si en la sexta "Investigación Lógica» Husserl afirma que la evidencia es una «vivencia de verdad $»^{41}$, que es como decir que es porque hay verdad que puede o no haber evidencia, Ortega, en cambio, apunta lo siguiente: «Mi visión —mi percepción visual— me da esas cosas. Lo que yo entiendo cuando he pensado lo encuentro en mi visión: advierto, pues, la identidad entre lo pensado y las cosas en mi visión dadas. El acto en el cual veo, hallo esa identidad es la evidencia. Como en la visión veo colores en la evidencia veo la identidad entre lo pensado y las cosas $»^{42}$. Hasta aquí no habría otro problema que el de la traducción en términos de «pensar» $\mathrm{y}$ «cosas» de lo que en términos husserlianos es «identidad» y «estado de cosas», donde la verdad es la concordancia entre «lo entendido y el dato como tal». Pero luego Ortega afirma: «Toda verdad se funda en un acto de evidencia». Lo cual contrasta con la afirmación husserliana de que no todo juicio verdadero es evidente ${ }^{43}$.

38 CP 5.444.

39 OC, VII, p. 500.

40 OC, vII, p. 499.

41 Husserl, E. (1999), Investigaciones lógicas, vol. 2, ed. de García Morente, M., Gaos, J. Madrid: Alianza, §39, p. 686.

42 OC, vII, p. 521.

43 Cfr. también Husserl, E. (1999), Investigaciones lógicas, vol. 1, ed. de García Morente, M., GAos, J. Madrid: Alianza, «Prolegómenos a la lógica pura», cap. vIII, § 51, p. 163: «Así como en la esfera de la percepción el no ver no coincide en modo alguno con el no ser, tampoco la falta de evidencia significa falta de verdad. La vivencia de la concordancia entre la mención 
De ello podemos inferir que Ortega carga con el que en los «Prolegómenos» aparece señalado como tercer prejuicio psicologista, y no es para nada casual que Husserl incluya a Meinong (el otro punto de referencia de Ortega) entre quienes asumen la lógica como teoría de la evidencia. Sin embargo, Ortega pretende mantener la instancia antisubjetivista pero imprimiendo una torsión «raciovitalista» a la fenomenología y, un poco más adelante, afirma: «No es, pues, un impulso subjetivo quien me mueve a declarar verdaderos mis pensamientos de las cosas, sino las cosas quienes dan la garantía a mi pensamiento».

Y para concluir esta primera parte acerca de la recepción y reelaboración del pragmatismo, vale la pena acudir a la lección vII, donde el sistema de la razón vital aparece mencionado entre las ciencias fenomenológicas o puramente descriptivas, que se distinguen de las ciencias de realidad (como por ejemplo, las ciencias físicas). Entre las descriptivas figuran unas archiconocidas como la lógica, la ontología y la matemática, otras poco conocidas como la "geometría de los colores», y una nada conocida, que — afirma Ortega - es

«la que yo llamo "sistema de la razón vital", cuyo problema algo difícil de exponer no ha sido que yo sepa descubierto hasta ahora, se entiende descubierto formalmente; gérmenes ocultos y trazos de él han andado y andan rodando por otras ciencias o formando esa zona pelúcida del conocimiento científico que tanto ocupaba a estos últimos tiempos bajo el nombre de Weltanschauung o idea del mundo, y en forma aún más pobre y más absurda en el llamado "pragmatismo" ${ }^{44}$.

\section{ZUBIRI Y EL PRAGMATISMO: REFERENCIAS POLÉMICAS INICIALES Y COINCIDENCIAS INSOSPECHADAS FINALES}

Ahora sí que podemos hacer entrar en escena a Zubiri, intentando delimitar el espacio en el que podrán salir a luz las afinidades con Peirce hasta ahora solo anunciadas. Para ello es indispensable mostrar cuán lejos está la posición de Peirce del voluntarismo. Pues este último fungió como dispositivo de lectura del pragmatismo en un escrito del año 1919 que Zubiri presentó en el año 1926 como trabajo de investigación en la oposición para la cátedra de Historia de la Filosofía de la Universidad Central de Madrid. Y no es casual que la fuente principal en la elaboración del texto haya sido — según ha sido señalado por Antonio Pintor-Ramos ${ }^{45}$ - la edición francesa de Pragmatism de James. Ahora bien, en ese entonces, en esa etapa específica de su itinerario intelectual, Zubiri

y lo presente en sí mismo y por la mención mentado, o entre el sentido actual del enunciado y la situación objetiva presente en sí misma, es la evidencia; y la idea de esta concordancia es la verdad. Pero la idealidad de verdad es lo que constituye su objetividad».

44 OC, vII, pp. 479-480. Recuérdese que la metáfora de los Dii consentes aparece al final de la lección VI del mismo curso.

45 Pintor-Ramos, A. (2006), Nudos en la filosofía de Zubiri. Salamanca: Publicaciones Universidad Pontificia de Salamanca, p. 55. 
da muestra de compartir la instancia antidogmática del pragmatismo, pero, una vez que ha reconocido su núcleo teórico en el principio de finalidad, según el cual la primacía corresponde a la acción, se pregunta: «¿Hacia dónde va dirigida la finalidad psíquica? Hacia la afirmación de la propia individualidad. Esto es, hacia la realización de los valores vitales. No hay más valor fundamental que el valor de la persona humana. Este es el pensamiento capital de donde arranca todo el sistema» ${ }^{46}$. Pregunta, respuesta y finalmente la exposición de una crítica que muestra la relación que guarda este texto del año 1919 con la memoria de Lovaina presentada en el año 1921 «Le problème de l'objectivité d'après Ed. Husserl». La crítica presente en el texto de 1919 se expresaba en estos términos: «la verdad es producto de la certeza, en vez de ser la certeza producto de la verdad». Y Zubiri no podía pasar por alto el derrotero de relativismo y, más aún, de escepticismo al que conducía una concepción psicologista de la verdad. A más de esto, muestra claramente que la crítica al monismo intelectualista no debe excluir, sino más bien hacer posible, «un intelectualismo cuyo ámbito fuese más modesto ${ }^{47}$, a saber, la búsqueda de «una nueva forma de vida intelectual», según señala Pintor-Ramos como rasgo distintivo de esta primera etapa. Una etapa que, sin embargo, es fenomenológica y «objetivista» y el vínculo entre la recepción de Husserl y la necesidad de una neoescolástica vital - y no sorprende que justo en estos pasajes aparezca mencionado Scheler- es tan estrecho que Zubiri llega a afirmar que «la analogía de nuestra situación espiritual y política con la que rodeó a San Agustín da hoy a muchas de sus ideas un interés primordial, y su original prueba de la existencia de Dios hace de él el primero de los fenomenólogos modernos» ${ }^{48}$.

La figura de Husserl juega un papel protagónico y constituye el puente entre el texto del año 1919 y la memoria de Lovaina de 1921, en particular los «Prolegómenos a la lógica pura». Aquí interesa destacar el hecho de que, distanciándose del pragmatismo en la versión de James, el joven Zubiri exhibe una mayor adherencia a las Investigaciones lógicas respecto a su maestro Ortega, tal y como lo evidencian las páginas de la memoria de Lovaina, en particular las dedicadas a la exposición de los tres prejuicios psicologistas que están redactadas al hilo de los «Prolegómenos» ${ }^{49}$.

Si esta es la crítica al pragmatismo, entendido sin ambages como psicologismo, tal como se perfila en la etapa «objetivista», ahora merece ser mencionado un pasaje del importante texto del año 1942 titulado «Nuestra situación

46 El pasaje se halla en la p. 56 del trabajo mecanografiado custodiado en la Fundación Xavier Zubiri.

47 Sobre este aspecto, véase el ya citado volumen de Pinto-Ramos (p. 73) que pone en relación este mismo pasaje con la reseña del libro de LANDSBERG, P. L. La Edad Media y nosotros, en Zubiri, X. (1999), Primeros escritos (1921-1926). Madrid: Alianza, pp. 373-381, p. 380 (de ahora en adelante PE): «Necesitamos una nueva disciplina que restablezca el primado de la inteligencia sobre la voluntad».

48 PE, pp. 380-381.

49 PE, pp. 51-56. 
intelectual», en el que el pragmatismo aparece como una prolongación del positivismo, que, a partir del vínculo que liga la ciencia a la previsión, por así decirlo "pervertiría» el criterio de verdad con el criterio de eficacia. Pero en el diagnóstico de una situación intelectual europea, cuyo primer síntoma de crisis es la falta de unidad, está involucrado también el historicismo. De particular interés es el gesto con el que Zubiri remite las tres corrientes corresponsables de la crisis a la triple estructura de la verdad:

«Positivismo, pragmatismo e historicismo son las tres grandes desviaciones a que en una u otra forma se halla expuesta la verdad por su triple estructura intelectual. La verdad es expresión de lo que hay en las cosas; y entendidas éstas como meros datos empíricos, se desliza suavemente hacia el positivismo. La verdad no se conquista sino en un modo de interrogar a la realidad; y entendido este interrogatorio como una necesidad humana de manejar con éxito el curso de los hechos, se deriva hacia el pragmatismo. La verdad no existe sino desde una situación determinada; entendida ésta como un estado objetivo del espíritu, se sumerge en el historicismo» ${ }^{50}$.

Como es notorio, el modo como Zubiri neutraliza la degeneración de los tres aspectos de la verdad consiste en retrotraerse hacia una verdad radical y primaria, es decir, la constitutiva inmersión de la inteligencia en las cosas, que queda especificada como «religación primaria y fundamental de la existencia ${ }^{51}$. Resulta fácil reconocer en semejante definición las huellas del magisterio heideggeriano - no hay que pasar por alto el hecho de que «ser», «mundo» y «teoría» no se definen como ideas ya hechas, sino como los tres grandes problemas, como las tres inquietudes intelectuales, que, sin embargo, imponen la necesidad, no solo teórica, de colmar el Abgrund, tal como emerge del final de «Nuestra situación intelectual»:

«La existencia del hombre actual es constitutivamente centrífuga y penúltima. De ahí el angustioso coeficiente de provisionalidad que amenaza disolver la vida contemporánea. Pero si, por un esfuerzo supremo, logra el hombre replegarse sobre sí mismo, siente pasar por su abismático fondo, como umbrae silentes, las interrogantes últimas de la existencia. Resuenan en la oquedad de su persona las cuestiones acerca del ser, del mundo y de la verdad. Enclavados en esta nueva soledad sonora, nos hallamos situados allende todo cuanto hay, en una especie de situación trans-real: es una situación estrictamente trans-física, metafísica. Su fórmula intelectual es justamente el problema de la filosofía contemporánea $»^{52}$.

Ahora bien, si en la obra maestra del año 1962, a la que Zubiri confiará la formulación de la situación trans-física, a saber, Sobre la esencia, la referencia polémica al pragmatismo desaparece, así como las inquietudes intelectuales antes mencionadas se desplazan del «ser» a la «realidad», hay algo que queda,

50 Zubiri, X. (2004 ${ }^{12}$ ), Naturaleza, Historia, Dios. Madrid: Alianza, p. 44 (de ahora en adelante NHD).

51 NHD, p. 50.

$52 \quad$ NHD, pp. 56-57. 
es decir, la intuición de que el camino a seguir para el renacimiento de la metafísica tiene que pasar necesariamente por un replanteamiento del concepto de «físico». Este mismo se ejerce, entre los distintos lugares de frecuentación zubiriana que van de Aristóteles a Husserl, de Enrique de Gante a Suárez, de Leibniz al existencialismo - por mencionar solo algunos- a través del comentario del mismo fragmento aristotélico analizado por Heidegger ${ }^{53}$ (Física B, 1) y del libro delta de la Metafísica. No pudiendo detenernos en todos los pasajes a través de los cuales Zubiri toma distancia de la estrategia heideggeriana de traducir ousía con Seiendheit, nos limitamos a aludir a la divergencia acerca de la interpretación del concepto de physis que se deriva de un distinto modo de entender la motilidad. Pues mientras que para Heidegger la cuestión relativa a la physis de los physei onta no apunta a las propiedades que se hallan en el ente de esta especie sino que plantea el problema del ser de este ente, para Zubiri, en cambio, el modo de actuar de los entes está determinado por sus propiedades. Sin embargo, no es el dato empírico - la prueba de Antifonte ${ }^{54}$ citada por Aristóteles- de que de una cama plantada, si algo tuviera que brotar, ello sería un castaño y no una cama, lo que induce a Zubiri a identificar la esencia con las propiedades «físicas» (o mejor dicho constitutivas). Y ello porque la cuestión de la motilidad ha sido desplazada del origen de la cosa al modo de existir y de actuar $^{55}$. Que el modo de actuar en algunos casos pueda configurarse como generación, y como generación de esencia, es una cuestión ulterior que concierne solo a las esencias quiddificables, las especies, pero no a la esencia en sentido estricto $^{56}$. Por otra parte, esta última es para Zubiri una estructura constitutiva, un sistema clausurado y coherencial de notas que no tiene nada que ver con el arrýthmiston, con lo que es falto de constitución y que, como tal, sería, según el sofista Antifonte, más ente que lo constituido (rythmós). En pocas palabras, el concepto zubiriano de «físico» no se deja asimilar ni al arché de los presocráticos, ni al arrýthmiston de Antifonte, ni a la materia que funge como substrato,

53 Heidegger, M. (1939), Vom Wesen und Begriff der physis. Aristoteles, Physik B 1, en ID. (1976), Wegmarken, GA, Bd. 9, hrsg. von HerrmanN, F. -W. Frankfurt a. M.: Klostermann.

54 D.K. 87 B 15.

55 A este respecto, Antonio González destaca la relevancia metafísica de la técnica actual que obliga a revisar el sentido de lo que sea naturaleza, y "para Zubiri, la naturaleza es cosa, pero cosa en el sentido de cosa-realidad. Y por cosa-realidad entiende Zubiri simplemente aquellas cosas que actúan formalmente por las propiedades que tienen, sea cualquiera su origen». González trae a colación el ejemplo que proporciona Zubiri de la insulina. Considerado que la insulina que se produce artificialmente en un laboratorio actúa al igual que la insulina que se produce en los islotes de Langerhans del páncreas, ambas son cosa-realidad, que se distinguen de la cosa-sentido. [GonzÁLEz, A. (2010), «La reflexión de Zubiri sobre la técnica», Rocinante, 5, p. 55].

56 Zubiri, X. (2008), Sobre la esencia. Madrid: Alianza, p. 234 (de ahora en adelante $\mathrm{SE}$ ): «No solamente no es evidente a priori que todas las realidades tengan esencia constitutiva multiplicable, sino que de hecho hay, por un lado, clases naturales, esto es, esencias constitutivas meramente repetidas, que no están constituidas en especie, y por otro lado hay esencias constitutivas que no son especiables, que no son quiddificables, precisamente por ser "únicas"”. 
ni tampoco «a la forma y a la especie en conformidad con la definición» ${ }^{57}$. Este último pasaje representa no solo una consciente toma de distancia de la posición aristotélica según la cual hay conocimiento solo de lo universal, sino también la ocasión de delimitar el espacio antepredicativo para un logos nominal constructo, a saber, para un logos que tiene que ver con constelaciones de notas y no con géneros próximos y diferencias específicas, con nombres y no con definiciones, y que, sin embargo, no por ello se ve negada la vía del conocimiento. Muy al contrario, semejante logos alcanza la ultimidad de lo individual. Claro que no con una definición y es por eso por lo que la corrección a Aristóteles debería rezar así: de lo particular no hay definición, pero sí hay conocimiento.

La esencia es un constructo de notas constitutivas ligadas por una unidad de coherencia. Esto último constituye un nivel que, a juicio de Zubiri, es más originario que el de subsistencia. Pero de la superación de las nociones de aseitas y de perseitas, nos ocuparemos más adelante, y ello porque serán ocasión de una confrontación entre Zubiri y Peirce en torno al concepto de "precisivo». Por ahora, empecemos a señalar algunos puntos de contacto.

Uno de ellos está íntimamente relacionado con la confrontación que ambos realizan con la escolástica, adoptando una posición realista que, sin embargo, se determina como crítica de aquellos intentos que, a su juicio, han faltado de radicalidad en la vía escogida para apresar y para definir el estatuto de la esencia individual. Pero antes de detenernos en el diálogo que entablan con sus interlocutores privilegiados, no podemos pasar por alto el hecho de que tanto Zubiri como Peirce excluyen que la vía hacia la esencia pueda recorrerse a través del concepto de especie. Ya hemos visto que Zubiri habla de esencias constitutivas «meramente repetidas, que no están constituidas en especie» y de «esencias únicas» que no son especiables. Por su parte, Peirce ha dedicado sus últimos años de vida a hallar una lógica de los íconos y de los índices, anterior a la lógica de los símbolos. Con semejante lógica Peirce apuntaba a dar cuenta de lo razonable en todo su alcance, y ello corrigiendo, según se lee en un manuscrito, el «más fatal error» de la historia de la filosofía, nacido con el «árbol de Porfirio», a saber, la pretensión de alcanzar el individuo singular a través de una dialéctica hecha de géneros y especies ${ }^{58}$. Merece ahora nuestra atención lo que un intérprete de Peirce como Maddalena califica como «revisión pragmatista» de un supuesto de la filosofía escolástica, a saber, la distinción escotista entre realidad y existencia. Si para Scoto, dicha distinción servía para explicar la generalidad de la realidad y la contracción de esta generalidad en el

57 Aristóteles, Física, B, 193 a 29-32. Se remite nuevamente al ya citado comentario de Heidegger, que señala que la distinción arrythmiston-rythmos se mantiene solo aparentemente en la declinación aristotélica hyle-morphé y ello porque Aristóteles introduce la cuestión del carácter de kinesis de la physis (pp. 267-269).

58 MS. 659: 38-39. Sobre este aspecto, cfr. el ya citado libro de Giovanni Maddalena (p. 73), quien destaca la analogía entre semejante desarrollo conceptual dialéctico y la teoría de los conjuntos, donde se halla «la misma dinámica y la misma dramática imposibilidad de aferrar el individuo dentro de la "verdadera continuidad" de los universales». 
individuo, para Peirce, en cambio, es la generalidad el auténtico conocimiento. Sin embargo, la distinción permanece en la descripción de las modalidades metafísicas: las esencias son posibles (no deben respetar el principio de contradicción), la existencia es actual (sujeta al principio de contradicción y de tercio excluso), la realidad es necesaria (evita el tercio excluso). Y concluye:

«Más allá de la construcción de lógicas paraconsistentes e intuicionistas, la distinción entre esencia, existencia y realidad permite emprender una vía para la comprensión de la creatividad humana en cualquier ámbito. Pues esta puede dar realidad a ciertas esencias y, bajo muchos aspectos aunque no bajo todos, puede hasta otorgar un cierto tipo de existencia, como en el caso de los personajes literarios o de los objetos tecnológicos » ${ }^{59}$.

Con semejante cita se nos vuelve aún más fácil proseguir en paralelo con Zubiri, quien no solo se confrontó con Suárez en busca de un concepto radical de esencia individual sino que lo hizo llamando a colación el espectro, es decir, uno de los tres modos de irrealidad (ficción, idea, espectro) que serán objeto de examen en el curso del año 1967 «El hombre: lo real y lo irreal» ${ }^{60}$.

Una vez aclarado que la apariencia es más que un ens rationis y, sin embargo, no es realidad, puesto que si es apariencia no tiene existencia "de suyo», sino más bien una existencia que se apoya en aquello de lo que es apariencia, Zubiri puede disolver la ambigüedad presente en los dos modos de entender la esencia: como realidad y como esencia en sentido estricto: «Realidad significa el carácter de ser "de suyo"; es, pues, la propiedad, o, mejor dicho, el carácter trascendental de la cosa: es la trascendentalidad misma. Esencia, en cambio, es el quid real, el contenido determinado de la cosa en función trascendental ${ }^{61}$. Entonces Júpiter que aparece como auriga se apoya en la «suidad», en el carácter trascendental y no en la aptitud para existir, lo cual contrasta con el supuesto de la escolástica según el cual el orden trascendental es el orden del ente real nominalmente considerado, el orden del ente apto para existir ${ }^{62}$. No es baladí recordar en este contexto que Zubiri se expresó en euskera hasta los seis años y que en su ejemplar del Diccionario vasco-castellano insertó dos breves anotaciones: una donde está el término berez traducido con "de suyo», y otra donde está el término gai, entre cuyas acepciones hallamos «el quid, el motivo, el fundamento, la esencia» ${ }^{63}$.

Así mismo, no responde a una mera curiosidad señalar aquí la preferencia de Peirce por el vasco, lengua en la que no hay sino poquísimas palabras que sean verbos ${ }^{64}$. Pues en su ideal de lengua, un ideal de lengua inspirado en la

59 Ibid., p. 233.

60 Zubiri, X. (2005), El hombre lo real y lo irreal, ed. de Conill, J. Madrid: Alianza (de ahora en adelante HRI).

61 SE, p. 460.

62 SE, p. 387.

63 Acerca de las raíces vascas del pensamiento zubiriano, cfr. ElLacuría, I. (1980), «Una nueva obra filosófica del vasco Xavier Zubiri», Deia y Conominas, J., Vicens, J. A. (2006), Xavier Zubiri. La soledad sonora. Madrid: Taurus, p. 710, nota 6.

64 CP 2.328. 
lógica de los relativos - y dócil a ser transcrita en grafos existenciales- las proposiciones tendrían que unir nombres-verbos (o símbolos) e índices, como por ejemplo pronombres selectivos correspondientes a cuantificadores ${ }^{65}$. Semejante intento de atenuar la demasiada atención que las lenguas indoeuropeas prestan a la distinción entre nombre y verbo conlleva la ausencia o, por lo menos, la innecesidad de la cópula. Con un salto hacia Inteligencia y logos, el segundo volumen de la trilogía que vio la luz en el año 1982, podríamos pensar en el segundo de los tres tipos de juicios analizados por Zubiri, a saber, los juicios proposicionales (los otros dos son los «posicionales», como por ejemplo ¡Fuego!, que no es una denominación sino una afirmación denominativa de lo real aprehendido en su totalidad; y los «predicativos» para los que vale la conexión A-B, donde A es independiente de B). Los ejemplos de juicios proposicionales que pone Zubiri son máximas latinas (corruptio optimi pessima; omnia praeclara, rara; varium et mutabile sempre femina), proverbios españoles como "genio y figura, hasta la sepultura»; "para verdades el tiempo», pero también invocaciones religiosas del tipo «Tú, el único Santo, el único Señor»; «Tú, Dios mío»; «Tú, Señor» ${ }^{66}$. En estos juicios que prescinden de la cópula - y Zubiri excluye que la cuestión pueda resolverse mostrando que en tales afirmaciones el verbo «ser» es tácito- hay dos momentos, el momento pro-puesto A (la corrupción del mejor, lo excelente, la mujer, Tú...) que es un momento real pero pro-puesto como término de una ulterior posición; y el momento B, que es una simple aprehensión irreal realizada en y por A. Ahora bien, en estos casos se trata de complexión AB y no de conexión A-B. Y ello porque, en el caso de los juicios proposicionales, $\mathrm{B}$ es un momento de la realidad de $\mathrm{A}^{67}$.

Volviendo al contexto de Sobre la esencia, cabe recordar que a la hora de distinguir entre esse essentiae, esse existentiae y esse logicum, Zubiri afirma que mientras que el esse logicum es abstracto, el esse essentiae es "precisivo ${ }^{68}$. Y aquí nos topamos con una afinidad entre Zubiri y Peirce que no es solo léxica sino también y sobre todo semántica. En «Issues of Pragmaticism» ${ }^{69}$, Peirce retoma un concepto nuclear de la tradición escotista, a saber el concepto de praecisus ${ }^{70}$ que ya había jugado un papel de suma importancia en el texto del año 1867 "On a New List of Categories». Solo que si en este parecía suficiente mostrar la diferencia que existe entre prescisión o abstracción (en su doble virtualidad de «neglect of» y de «attention to» un elemento), discriminación (distinción de significado) y disociación (conciencia de una cosa sin la conciencia simultánea y necesaria de la otra), a la altura del año 1905, Peirce destaca como uno de los

65 CP 2.289. De esta manera, una frase como «todo hombre ama una mujer» se convierte en «Cualquier cosa» (pronombre selectivo) «Es un hombre» (símbolo) «Ama» (símbolo) «Cualquier cosa» (pronombre selectivo) «Es una mujer» (símbolo) (CP 2.296).

66 ZuBIRI, X. (2002²), Inteligencia y logos. Madrid: Alianza, p. 155 (de ahora en adelante IL).

67 IL, pp. 156-157.

68 SE, pp. 385-386.

69 CP 5.438-463.

70 Sсото, Opus Oxon. III, XII, qu. única, «Utrum Christus fuerit homo in triduo». 
«Temas del pragmaticismo», una distinción a la que confía nada menos que el rescate del «buen navío de la filosofía de los filibusteros del mar de la literatura». Pues distinguiendo entre prescindir, prescisar, prescisión y prescisivo, por un lado, y precidir, preciso, precisión y precisivo, por otro, Peirce distingue entre disección en la hipótesis y expresión de la determinación. Y ello con vistas a

«evitar que la estirpe de "abstracto" sucumba bajo la doble carga de transmitir tanto la idea de prescisión como la muy importante idea, independiente de la anterior, de la creación de un ens rationis a partir de un epos pteroen - por birlar frase, para dar un nombre a una expresión del pensamiento no sustantivo- una operación que ha sido tratada como objeto del ridículo — esta abstracción hipostática - pero que da a las matemáticas la mitad de su fuerza ${ }^{71}$.

La diferencia entre prescisivo y precisivo es entonces la misma que hay entre una cosa blanca en general y el ser blanco. La abstracción hipostática es la que hipostasia una relación convirtiéndola en sujeto de ulteriores determinaciones. Por otra parte, y también aquí hallamos terreno para nuestra confrontación, el convencimiento de que la percepción no tiene nada de inmediato, sino que, por el contrario, es fruto de una inferencia abductiva, queda reforzado por su vínculo con la abstracción prescisiva, como en el caso de «es luminoso», mientras que la abstracción hipostática es la que transforma «es luminoso» en "hay luz aquí».

$\mathrm{Al}$ respecto cabe señalar que tanto Peirce como Zubiri se sirven del término percepto para indicar el carácter mediato de la percepción, y ello en el marco de una visión de la experiencia como algo «logrado» que no dado. Interesa destacar que al concepto de percepto se acompaña, por un lado, la distinción entre feeling y sensation y, por otro, la distinción entre dos momentos de la aprehensión: «aprehensión primordial» y logos. Además de esto, la firstness del feeling y la fundamentalidad de la aprehensión primordial comparten el carácter de inefabilidad. De ella Peirce decía que «es tan tierna que no puedes tocarla sin arruinarla " ${ }^{72}$. Lo primero es «lo que el mundo fue para Adán el día en que abrió los ojos, antes de que hubiera esbozado cualquier distinción, o se hubiera hecho conciencia de su propia existencia [...]. Cualquier descripción de él tiene que falsearlo» ${ }^{73}$. «Semejante conciencia podría ser meramente un olor, digamos el perfume de una esencia; o podría ser un infinito dolor de cabeza; podría ser la audición de un eterno silbido penetrante» ${ }^{74}$.

En el artículo de Spiegelberg antes mencionado, la confrontación entre la fenomenología de Peirce y la de Husserl hallaba justamente en el concepto de firstness uno de los elementos de incompatibilidad, incluso cuando el autor intentaba un acercamiento entre la primeridad y el «hyletic datum», pero no

\footnotetext{
71 CP 5.448.

72 CP 1.358.

73 CP 1.357.

74 CP 5.44.
} 
sin advertir la falta en Peirce de una idea de «knowledge as an "intentional" process», lo cual implicaría otra falta, es decir, la indistinción entre la cualidad sentida y la sensación de una cualidad, en el marco de una concepción monista de los fenómenos ${ }^{75}$. No es posible pasar aquí por todas las vicisitudes que atraviesa la noción de residuo hilético en el itinerario especulativo husserliano, que culmina en su abandono - y, junto con él, en la superación de un cierto sensualismo de los datos de Ideen I- una vez que dicha noción se ha vuelto innecesaria en el marco de la síntesis pasiva, donde la conexión es justamente interna a los fenómenos y la trascendencia de la cosa alude al carácter dinámico de la experiencia, ya que la cosa se manifiesta a través de síntesis temporales y asociativas ${ }^{76}$. Y, sin embargo, es justamente en polémica con las nociones de residuo hilético y de factum brutum como Zubiri va elaborando su idea de inteligencia sentiente. En semejante proceso, un paso significativo es el que da en el curso del año 1966 "Sobre la realidad», en el que apunta a sustituir el concepto de intuición por el de impresión, ya que lo sensible de la intuición —que a su juicio sería aquello de lo que se había olvidado Husserl no obstante la expresión "en carne y hueso» [leibhaft] — es tal por impresión ${ }^{77}$. En ese mismo curso, critica la interpretación «falsa» que Heidegger expone de la Crítica de la razón pura en Kant y el problema de la metafísica, que confirmaría la tradición de concebir la sensibilidad como residuo hilético ${ }^{78}$. En el primer volumen de la trilogía, publicado en el año 1980, Zubiri reiterará que la sensibilidad no es una especie de residuo hilético de la conciencia, como dice Husserl, ni un factum brutum, como la llaman Heidegger y Sartre, sino que es un momento intrínseco y formal de la intelección ${ }^{79}$.

Si bien hemos identificado una cierta afinidad entre Zubiri y Peirce en lo que concierne al empleo de la noción de «percepto», no podemos pasar por alto el hecho de que el límite que hallamos en el acercamiento entre la firstness y la estructura bipolar de la conciencia en Husserl, lo hallamos también entre

75 Spiegelberg, H. (1956), «Husserl's and Peirce's Phenomenologies: Coincidence or Interaction», p. 171 y p. 173: «By contrast, Husserl's conception of consciousness is fundamentally "bi-polar" (...). This allows Husserl not only to distinguish between acts and contents but also to pay special attention to the varying subjective appearances of the identical objective contents. It also yields a much more differentiated structure of the field of phenomena compared with Peirce's phenomenon of Firstness, which consists simply in a sequence of "seemings", without any structural depth or referential links. It is only Secondness and Thirdness that would seem to open up the possibility of phenomena comparable with Husserl's intentional patterns. Thus, seen from Husserl's perspective, Peirce covers at best half of the world of phenomena, namely the objective or intended pole of our consciousness. The other half, the subjective or intending pole of it, remains outside its scope».

${ }_{76}$ Sobre este aspecto y sobre la rehabilitación de la sensibilidad que ello comporta, cfr. Costa, V. (1999), L'estetica trascendentale fenomenologica. Sensibilità e razionalità nella filosofia di Edmund Husserl. Milano: Vita e Pensiero, en especial p. 196.

77 Zubiri, X. (2001), Sobre la realidad, ed. de Martínez, J. A. Madrid: Alianza, p. 21 (de ahora en adelante SR).

$78 \quad$ SR, p. 34.

79 Zubiri, X. $\left(2006^{6}\right)$, Inteligencia sentiente. Inteligencia y realidad. Madrid: Alianza, p. 85. 
la cualidad de sensación (Peirce) y la aprehensión primordial. Y ello porque el intento de Zubiri fue justamente el de radicalizar la alteridad de la realidad a través del concepto capital de "de suyo», al cual se liga, en la trilogía, la superación de la noción de intencionalidad con la de coactualidad y la de noético con noérgico. Podríamos decir que la aprehensión primordial de realidad, aunque se halla en un nivel más originario que el de la relación sujeto-objeto, aunque es compacta, directa, inmediata, estando en ella pro indiviso el momento individual-campal, sin embargo, está penetrada por la «secondness» de la coactualidad. Al respecto, conviene encomendarnos a la claridad de Diego Gracia:

«Aquí [en la aprehensión primordial] el ser humano no lleva la iniciativa. Muy al contrario, es lo aprehendido lo que se le impone de modo imperioso, haciéndose presente en la aprehensión. Por tanto, analizada desde el punto de vista formal, la aprehensión consiste en mera actualización de algo en la inteligencia. Lo que en el orden del logos, es decir, de los contenidos, era "libre creación", aquí, en la aprehensión primordial, y por tanto en el de la formalidad, es "mera actualización". ¿Qué es lo que se actualiza? Se actualiza lo aprehendido en el aprehensor y el aprehensor en lo aprehendido. De aquí que se trate, dice, de una "coactualización". Lo aprehendido se actualiza en la aprehensión no como siendo "en sí" lo que es (esto sería realismo en el sentido clásico de la palabra, es decir, "realismo ingenuo", que incluye no sólo forma sino también contenido), pero tampoco siendo simplemente "en mí" (esto sería, dice Zubiri, puro subjetivismo, "subjetivismo ingenuo", una de cuyas expresiones históricas fue el llamado psicologismo). En la aprehensión lo aprehendido se hace presente y sale por sus fueros no como "en sí", ni como "en mín" sino como "de suyo". Y a este de suyo que no es en sí es a lo que Zubiri llama "realidad" ${ }^{80}$.

Otra diferencia relevante emerge del empleo de la noción de percepto. Con ella, nos sale al encuentro una divergencia en la convergencia, es decir, las dos distintas definiciones del hombre, "animal de realidades» y logical animal, que ambos elaboran en el marco compartido del «emergentismo por elevación». En pocas palabras, si Peirce asume como rasgo distintivo del hombre la capacidad de realizar inferencias, Zubiri, en cambio, aun coincidiendo en la no inmediatez de la percepción, remite el logos no a un silogismo sino a la aprehensión dual y medial de realidad.

El ejercicio hermenéutico, que aquí se ha intentado, trata de evitar lo que pudiera ser una torpe tentativa de hacer encajar una figura en la otra. Nuestro objetivo no es otro que operar un salto más acá del practicalismo de cuño jamesiano que ha condicionado fuertemente hasta impedir del todo el encuentro entre Zubiri y una forma de realismo como la que Peirce reivindicaba para su propia posición. Y lo que aquí más interesa subrayar es, que es con base en un realismo radical y no ingenuo cómo ambos reconocen el peso y la «resistencia»

80 Gracia, D. (2010), «Zubiri en su contexto. O la difícil tarea de hacer metafísica a la altura del siglo xx», Rocinante, 5, pp. 28-29. 
de las construcciones libres. Otras dos citas y nos encaminamos hacia la conclusión. En una de las lecciones de Harvard, lección que apuntaba a reformar la dialéctica hegeliana haciendo hincapié en el momento de la secondness, Peirce exponía las categorías de «cualidad», «lucha» y «nous», y acerca de la lucha afirmaba lo siguiente:

«Al leer una demostración geométrica, si trazo la figura en mi imaginación, en lugar de dibujarla sobre un papel, es tan fácil añadir a mi imagen todas las líneas subsidiarias que haga falta, que me parece haber actuado sobre la imagen sin que esta haya ofrecido resistencia. Es fácil probar, sin embargo, que no es eso lo que sucede. Porque si la imagen no tuviera cierta capacidad de persistir tal como es y de resistirse a las metamorfosis, y si yo no percibiera su poder de resistencia, nunca me sería dado estar seguro de que la construcción con la que estoy tratando en una etapa de la demostración era la misma que tenía ante mi mente en una etapa anterior ${ }^{81}$.

Zubiri, por su lado, afirma, ya desde el curso «El hombre: lo real y lo irreal», que «la ficción más ficticia del mundo envuelve el momento físico de realidad en el que se inscribe». Y es precisamente por esto por lo que cobra gravedad el mundo de la ficción ${ }^{82}$. Una gravedad que, a su juicio, revelaba el carácter obsoleto del instrumento de la intencionalidad. De ahí pasará a la elaboración, en Inteligencia y logos, de los "perceptos», «fictos» y "conceptos», pero no sin insistir en el hecho de que lo real, cuando queda realizado como postulado, una vez realizado, posee más notas propias que las que están comprendidas en los conceptos, en los fictos y en los perceptos ${ }^{83}$. En Inteligencia y razón, que ve la luz por primera vez en el año 1983, la profundización en los modos de creación racional (imagen formal o modelo, hipótesis y postulado) lo llevará a detenerse en la geometría, entendida como intelección racional de la realidad espacial del campo perceptivo en su realidad profunda, consistente en un sistema libre de postulados $^{84}$. De semejante planteamiento emerge claramente la distinción y la relación que existe entre realidad campal y realidad en profundidad, entre la unidad del espacio pre-geométrico y la multiplicidad e independencia de los contenidos fundamentales postulados en el espacio geométrico, que, lejos de ser susceptible de ser intuido, es fruto de una creación libre ${ }^{85}$.

Concluimos dejando en suspenso muchos otros rasgos comunes, o por lo menos dignos de ser confrontados, como por ejemplo 1. la aplicación de la

81 CP 5.45 .

82 HRI, p. 29.

83 IL, p. 131.

${ }^{84}$ ZubiRI, X. (20012), Inteligencia y razón. Madrid: Alianza, p. 130 (de ahora en adelante IRA).

85 Para una profundización en la dúplice índole de la razón: por un lado, sujeta por su origen estructural a la impresión de realidad y, por otro, libre y creadora por lo que concierne al contenido de la intelección, véase Conill, J. (1991), El enigma del animal fantástico. Madrid: Tecnos, p. 185 y ss. 
categoría de «realidad» sin contenidos al fundamento ${ }^{86}$ y el Dios real de Peirce que es más real cuanto más vago y general ${ }^{87} ; 2$. la relación que guarda, por el lado de Zubiri, la facultad de la inteligencia sentiente y, por el lado de Peirce, el instinto como raíz profunda de la razón ${ }^{88}$ con un falibilismo que no es relativismo; 3. la doctrina peirceana de la continuidad y el concepto zubiriano de «religación» en su poder de atener al hombre a la realidad; 4. la expresión peirceana «in the long run» y la zubiriana «marcha de la razón»; 5. el concepto de verificación y, finalmente, 6. la instancia anticartesiana que se traduce para ambos en una referencia a San Agustín que, a su vez, se configura como inversión de la inversión hecha por Descartes ${ }^{89}$.

86 Zubiri, X. (2012), El hombre y Dios, ed. de Vargas Abarzúa, E. Madrid: Alianza, p. 183 (de ahora en adelante HD): «Dios es una realidad que está por elevación allende no sólo la diferencia de esencia y de existencia sino también allende su presunta identidad. Es que ser realidad consiste siempre en ser "de suyo"». Sobre este aspecto, véase la reciente introducción de Paolo Ponzio a la edición italiana de El hombre y Dios, en ZuBIRI, X. (2013), L'uomo e Dio, ed. de Savignano, A., Ponzio, P. Bari: Ed. Pagina, en especial p. xxiv, donde Ponzio ahonda en la superación por parte de Zubiri de todo reduccionismo ontológico y de toda explicación antropológica y cósmica de la existencia de Dios y ello porque «Zubiri emprende una tercera vía para la justificación de Dios que evita tanto la disociación como la fragmentación (...) hasta alcanzar una idea de Dios como realidad suprema. Realidad y no ente, porque también para el concepto de Dios vale ese criterio universal de la filosofía zubiriana según el cual el ser es solo un acto ulterior de lo real».

87 CP 6.496. Recuérdese que uno de los «Temas del pragmaticismo» es la distinción entre general y vago: a lo "general» no se aplica el principio del tercio excluso y a lo "vago» no se aplica el principio de contradicción. Por otra parte, cuando Zubiri destaca la «concreción» como uno de los caracteres de la realidad de Dios, quien "no es un vaporoso absoluto", aclara que «no se trata de tomar lo concreto como contrapuesto a lo abstracto, sino como absoluta concreción primaria. No es realidad concretizada sino absolutamente concreta. Su carácter absolutamente absoluto lleva consigo la absoluta concreción; concreción que no es constituyente de su realidad, sino, por el contrario, es un absoluto que en cuanto absoluto hace "brotar" (es un lenguaje antropomórfico inevitable) en sí mismo la concreción de lo absoluto» (HD, p. 185).

88 Remitimos al ya citado volumen de G. MADDALEnA, pp. 89-96, en especial p. 95: «El instinto tiene una naturaleza inferencial. No hay inmediatez en el instinto. El conocimiento inconsciente (los juicios perceptivos) ya es fruto de un juicio abductivo; con más razón los pensamientos conscientes son fruto de una determinación racional. ¿Cuál es entonces la diferencia entre un juicio abductivo, deductivo o inductivo y el instinto para la verdad? En el segundo caso, el juicio que se da concierne a la belleza y a la bondad de los signos que se nos presentan. Las grandes intuiciones, desde las de Galileo hasta la hipótesis de la realidad de Dios, son fruto de un juicio acerca de la belleza (a menudo acerca de la armonía) de una cierta hipótesis y acerca de la viabilidad de esa misma belleza».

89 Véase la referencia que hace Peirce a De civitate Dei en «Temas del pragmaticismo», en especial a la expresión si fallor sum como ejemplo de inferencia acrítica. Zubiri, por su parte, en un pasaje de Inteligencia y razón que apunta a señalar el entrelazamiento entre intellectus quaerens y encuentro, cita un pasaje del De Trinitate, XI, I: «Busquemos como buscan los que aún no han encontrado, y encontremos como encuentran los que aún han de buscar, porque cuando el hombre ha terminado algo no ha hecho sino comenzar» (IRA, p. 261). Sobre este aspecto, cfr. Ponzio, P. (2010), «El problema de la verdad en la "inteligencia de la actualidad" de Xavier Zubiri», Rocinante, 5, pp. 153-172, en especial p. 169 y ss. 
Por ahora, hemos vislumbrado en la decisión de no partir ni de datos sensibles puros ni de verdades de razones una reformulación del concepto de experiencia que, justamente por el peso que se les reconoce a las construcciones, se perfila como un antídoto eficaz contra el relativismo y el dogmatismo.

De desencuentro se ha tratado, lo hemos dicho desde el principio. No sabemos qué efecto habría tenido en Zubiri una lectura de Peirce no mediada por James. Por cierto el «voluntarismo» habría resultado ser un dispositivo de lectura incorrecto para quien afirmaba que «lo real es aquello a lo que, más pronto o tarde, aboca la información y el razonamiento, y que en consecuencia es independiente de los antojos (vagaries) tuyos o míos» ${ }^{90}$.

Università della Calabria

María Lida Mollo

marialidamollo@yahoo.it

[Artículo aprobado para publicación en este número extraordinario en noviembre de 2014]

90 «Algunas consecuencias de cuatro incapacidades» (CP 5.311). 